\title{
The relationship between: occupational status, biological condition and androgen hormone level among Polish adult men: the Wroclaw Male Study
}

\author{
Monika Łopuszańska-Dawid, Alicja Szklarska, Halina Kołodziej, Anna \\ Lipowicz \& Ewa A. Jankowska
}

To cite this article: Monika Łopuszańska-Dawid, Alicja Szklarska, Halina Kołodziej, Anna Lipowicz \& Ewa A. Jankowska (2016): The relationship between: occupational status, biological condition and androgen hormone level among Polish adult men: the Wroclaw Male Study, The Aging Male, DOI: 10.1080/13685538.2016.1220519

To link to this article: http://dx.doi.org/10.1080/13685538.2016.1220519

曲 Published online: 01 Oct 2016.

Submit your article to this journal $₫$

Q View related articles ¿

View Crossmark data $₫$ 


\title{
The relationship between: occupational status, biological condition and androgen hormone level among Polish adult men: the Wroclaw Male Study
}

\author{
Monika Łopuszańska-Dawid ${ }^{1}$, Alicja Szklarska ${ }^{1}$, Halina Kołodziej ${ }^{2}$, Anna Lipowicz $^{2}$, and Ewa A. Jankowska ${ }^{3}$ \\ ${ }^{1}$ Polish Academy of Sciences, Warsaw, Poland, ${ }^{2}$ The Faculty of Biology and Animal Science, Institute of Biology, Wroclaw University of \\ Environmental and Life Sciences, Wroclaw, Poland, and ${ }^{3}$ Department of Heart Diseases, Wroclaw Medical University, Wroclaw, Poland
}

\section{Abstract}

Population health and its determinants are one of the major challenges to social and economic policy. The aim of this study was to investigate the relationship between occupational activity and biological condition in adult working Polish men. The participants of the study were 300 men (30-65 years), healthy inhabitants of the city of Wroclaw, Poland. Seventeen measures of biological condition were examined. The subjects were divided into three different occupational groups: professionals, soldiers and skilled workers. A comparison of biological age profiles of three occupational groups showed that in the majority of characteristics, professionals had the youngest biological age, whereas skilled workers had the highest biological age. The results for soldiers were not as unambiguous, but biological parameters were generally closer to those for professionals. Inborn biological predispositions and longterm impact of the working environment can influence on the biological condition of various professional groups. Knowledge of the determinants of biological condition might result in efficient use of predisposition to work or may be of help in extending their time of work ability.
\end{abstract}

\author{
Keywords \\ Professionals, soldiers, skilled workers, \\ biological condition, hormonal profile, \\ workplace environment, Poland
}

\section{History}

Received 1 June 2015

Revised 22 June 2016

Accepted 1 August 2016

Published online 8 September 2016

\section{Introduction}

Both employment and unemployment have a significant impact on health [1-3]. The effect of the workplace environment on the health of workers has been widely discussed in the literature [4-6]. The dependency between the biological condition of workers on the one hand and the physical and psychological conditions of the work performed on the other has not been extensively explored.

There have been many studies on the adverse effect of broadly conceived external physical working conditions on the risk of developing different types of illness. There is evidence that the risk of developing cardiovascular diseases is increased by adverse working conditions such as working in old offices with poor lighting and air quality [7]. The effects on health of excessive physical exertion at work have been widely analyzed, although the results of these studies are often ambiguous and even contradictory. Some of them have

\footnotetext{
*Department of Anthropology and Health Promotion, Faculty of Physical Education, Jozef Pilsudski University of Physical Education in Warsaw, Poland.

Address for correspondence: Dr Monika Łopuszańska-Dawid, Department of Anthropology and Health Promotion, Faculty of Physical Education, Jozef Pilsudski University of Physical Education in Warsaw, Marymoncka 34, 00-968 Warsaw 45, Poland. Tel: +48 (22) 83404 31. E-mail: mlopdaw@gmail.com
}

found that work-related physical activity reduces the risk of developing cardiovascular diseases $[8,9]$ although others have found that it increases the risk $[10,11]$. Also, there are few papers, which have detected any effect at all $[12,13]$. There has also been a good deal of discussion about the effects on health of repetitive work such as garment sewing or of work performed while standing $[14,15]$. Other studies have focused on the effects of particular adverse work conditions in certain occupations or burden of cancer and mortality of specific occupation groups $[16,17]$.

The effect of psychosocial work conditions on the health of workers has also been widely explored [18-21]. Psychosocial conditions have become more significant for worker's health than physical conditions because of the shift from manual to non-manual work due to automation, and also because of increased regulation and monitoring of physical and chemical conditions of the working environment. Both job satisfaction and fulfillment have a major effect on the biological condition of workers, regardless of the type of work performed. For example, they affect physiological parameters such as levels of testosterone or circulating immune cells, including natural killer cells, B lymphocytes and T lymphocytes [22,23]. Most of the studies that have been reported in the literature deal with the effects of the work environment on single parameters related to the biological condition of workers and prevention of 
workplace stress might decrease various disease incidences. Few studies have attempted to analyze complex multifactorial relationships between working conditions and biological conditions. Certain effects of the psychosocial working environment on physiological changes have been shown by Hansen et al. [24]. Physiological changes in concentrations of hormones and other biological parameters in blood or urine have also been used as an indicator or biomarker of the changes in the organism occurring from the exposure to the psychosocial changes. Physiological systems activated by occupational stressors may both restore and harm the body [24,25].

The aim of the present study was to investigate the relationship between occupational activity and biological condition in adult working Polish men, with particular importance to their gonadal-adrenal activity.

\section{Materials and methods}

The study group consisted of 355 active, healthy men, inhabitants of the city of Wroclaw, Lower Silesia, Poland, aged 30-65 years. The study proposal was approved by the Bioethical Committee of Medical University in Wroclaw, Poland (approval number: 477/2000). The men were medically examined in 2000 and in 2010/11 under project The Wroclaw Male Study in the Silesian Center for Preventive Medicine "DOLMED' in Wroclaw. The group was ethnically homogenous with no national, linguistic, religious or racial minorities sample of men. Men included in the study did not suffer from any essential chronic diseases and had not done so in the past (in particular, those resulting in hormonal pathologies). Subjects taking medications, in particular, drugs interfering with hormone metabolism were excluded from the analysis. On physical examination they presented no pathologies. The men were not selected for any biological parameters or in another way. Finally, from the analysis $15.5 \%$ men were excluded and final database for further analysis included 300 men.

Eleven measures of general biological condition and six hormonal parameters were examined. General biological condition was evaluated on the basis of the following parameters:

- Body height, recorded in centimeters and measured in the standing position using an athropometer (B-v: Basisvertex)

- Body Mass Index (BMI=body weight $[\mathrm{kg}] /$ body height $[\mathrm{m}]^{2}$ )

- Fat distribution, recorded as Waist Hip Ratio $(\mathrm{WHR}=$ waist circumference $[\mathrm{cm}] /$ hip circumference [cm])

- $\quad$ Systolic and diastolic blood pressure, recorded in $\mathrm{mmHg}$ and measured in the sitting position using an Avionics manometer after a rest period of at least $5 \mathrm{~min}$, two measurements were averaged

- Eye-hand co-ordination (EHC), recorded as the number of errors per minute and measured with a Piórkowski apparatus with a setting of 93 light signals per minute

- Biochemical blood parameters, including:

- total cholesterol $(\mathrm{TCH})[\mathrm{mg} / \mathrm{dl}]$

- triglycerides (TGL) [mg/dl]

- high-density lipoprotein (HDL) $[\mu \mathrm{mol} / \mathrm{L}]$
- low-density lipoprotein (LDL) [mg/dL]

- glucose $[\mathrm{mg} / \mathrm{dL}]$

The hormonal parameters included the following:

- insulin-like growth factor 1 (IGF-1) [ng/mL]

- total testosterone (TT) $[\mathrm{ng} / \mathrm{mL}]$

- free testosterone (FT) $[\mathrm{pg} / \mathrm{mL}]$

- $\quad$ sex hormone-binding globulin $(\mathrm{SHBG})[\mathrm{nmol} / \mathrm{L}]$

- estradiol (E2) [pg/mL]

- dehydroepiandrosterone sulfate (DHEAS) [ng/mL]

All hormones were measured by radioimmunoassay in the Endocrine Laboratory at Wrocław Medical University. Free testosterone was calculated using the method described by Vermeulen et al. [26].

The subjects were divided into three occupational groups on the basis of occupational position and level of education: (1) professionals; (2) soldiers; and (3) skilled workers. The professionals included highly educated men specializing in high-prestige occupations, such as scientists, educators, physicians, lawyers and managers. The soldiers included those in the uniformed services and related occupations, such as soldiers, sailors, customs officers and armed bodyguards. The skilled workers included men performing occupations requiring a high-level of efficiency, skills and experience, such as plumbers, mechanics and hairdressers. They most often had attended vocational schools. The occupational groups described above were formed on the basis of the type of work performed and the prestige attached to it. Professionals perform mainly mental work consisting of decision making, directing other people, and responsibility for other people and property. Skilled workers, on the other hand, perform mainly physical work. Soldiers represent a middle ground between the other two groups, as their occupations include both mental and physical work.

Other data gathered on the subjects included data on socioeconomic status including: (1) level of education (three categories: tertiary, secondary, vocational) and (2) marital status (two categories: married, non- married), as well as information on life style, including: (1) cigarette smoking (two categories: yes, no), (2) alcohol consumption (three categories: weekly or more, occasionally, no) and (3) leisure time physical activity (two categories: yes, no), and information about character of work: (1) job requiring independent decisions, (2) work associated to personnel management, (3) repetitive work, and (4) work physically hard (two categories: yes, no - each of these). Beside information about the psychical condition of men were also added, namely: (1) general life satisfaction (three categories: low, medium, high) and (2) approach to life (three categories: optimist, pessimist, mixed).

\section{Statistical analyses}

The significance of differences in biological variables between occupational groups was assessed using one-way analysis of variance. Correlations between biological parameters and calendar age were measured by correlation coefficients $r$. Differences were considered significant if $p$ was less than or equal to 0.05 . In the analyses were applied following levels of significance $* p \leq 0.05$; ** $p \leq 0.01$; *** $p \leq 0.001$.

The biological variables for three occupational groups were compared to age-specific norms in accordance with 
the method described by Borkan and Norris [27]. Changes related to the aging process are a reliable indicator of biological condition. The biological age of an individual for a given trait can be estimated on the basis of the deviation of that trait from the age-specific norm. An individual is considered biologically older if their values for a given trait are characteristic of individuals older than their calendar age. Likewise, biologically younger individuals have values characteristic for younger individuals. The first step in estimating biological age is constructing a simple regression equation for each trait as a function of calendar age. Then the values for each individual are compared to the reference values to determine biological age for each trait. Comparison among traits was made by standardizing the values for the separate traits in terms of standard deviations from the mean value. Because values for some of the traits decrease with calendar age, giving a reference line with a negative slope, values for those traits were multiplied by -1 . The use of standardized scores allows the simultaneous representation of all of the biological parameters on a single profile graph. The significance of differences between the means for each trait was determined using Student's $t$-test.
Data were analyzed using the STATISTICA 10.0 software package (data analysis software system, StatSoft Inc., Tulusa, $\mathrm{OK})$.

\section{Results}

Frequencies for socio-economic, lifestyle parameters and characteristics of work and psychological condition for each occupational group are presented in Table 1. All of the professionals had received tertiary education. For the soldiers, about half had received tertiary education, while the other half have received secondary education. Three quarters of the skilled workers had received vocational education, and most of the rest secondary education. Few of them had received tertiary education.

The percentage of non-married individuals was highest for skilled workers, and lowest for professionals. About half of the skilled workers smoked cigarettes. Only a quarter of the professionals did. The percentage of individuals who consumed alcohol once a week or more was highest for skilled workers, with about half reporting that level of consumption. The percentage of individuals who consumed alcohol occasionally was highest for professionals. The percentage of individuals who did not consume alcohol at

Table 1. Socio-economic parameters, lifestyle parameters, characteristics of work and psychological condition by occupational group (in numbers, percent).

\begin{tabular}{|c|c|c|c|}
\hline & $\begin{array}{c}\text { Professional } \\
N=115 \\
N(\%) \\
\end{array}$ & $\begin{array}{l}\text { Soldiers } \\
N=55 \\
N(\%)\end{array}$ & $\begin{array}{c}\text { Skilled workers } \\
\begin{array}{c}N=130 \\
N(\%)\end{array}\end{array}$ \\
\hline \multicolumn{4}{|l|}{ Level of education } \\
\hline Tertiary & $115(100)$ & $30(54.5)$ & $2(1.5)$ \\
\hline Secondary & - & $25(45.5)$ & $38(29.2)$ \\
\hline Vocational & - & - & $90(69.2)$ \\
\hline \multicolumn{4}{|l|}{ Marital status } \\
\hline Married & $111(69.5)$ & $53(96.4)$ & $118(90.8)$ \\
\hline Non-married & $4(3.5)$ & $2(3.6)$ & $12(9.2)$ \\
\hline \multicolumn{4}{|l|}{ Cigarette smoking } \\
\hline Yes & $27(23.5)$ & $24(43.6)$ & $66(50.8)$ \\
\hline No & $88(76.5)$ & $31(56.4)$ & $64(49.2)$ \\
\hline \multicolumn{4}{|c|}{ Alcohol consumption } \\
\hline Weekly or more & $39(34.2)$ & $23(43.4)$ & $61(52.1)$ \\
\hline Occasionally & $52(45.6)$ & $13(25.5)$ & $33(28.2)$ \\
\hline No & $23(20.2)$ & $17(32.1)$ & $23(19.7)$ \\
\hline \multicolumn{4}{|c|}{ Leisure time physical activity } \\
\hline Yes & $107(93.0)$ & $54(98.2)$ & $110(84.6)$ \\
\hline No & $8(7.0)$ & $1(1.8)$ & $20(15.4)$ \\
\hline \multicolumn{4}{|c|}{ Job requiring independent decisions } \\
\hline Yes & $110(95.7)$ & $53(96.4)$ & $46(35.4)$ \\
\hline No & $5(4.3)$ & $2(3.6)$ & $84(64.6)$ \\
\hline \multicolumn{4}{|c|}{ Work associated to personnel management } \\
\hline Yes & $86(74.8)$ & $48(87.3)$ & $18(13.8)$ \\
\hline No & $29(25.2)$ & $7(12.7)$ & $112(86.2)$ \\
\hline \multicolumn{4}{|l|}{ Repetitive work } \\
\hline Yes & $15(13.0)$ & $12(21.8)$ & $83(63.9)$ \\
\hline No & $100(87.0)$ & $43(78.2)$ & $47(36.2)$ \\
\hline \multicolumn{4}{|c|}{ Work physically demanding } \\
\hline Yes & $6(5.2)$ & $15(27.3)$ & $97(74.6)$ \\
\hline No & $109(94.8)$ & $40(72.7)$ & $33(25.4)$ \\
\hline \multicolumn{4}{|c|}{ General life satisfaction } \\
\hline Low & $3(2.6)$ & $5(9.3)$ & $7(5.4)$ \\
\hline Medium & $41(36.0)$ & $27(50.0)$ & $85(65.9)$ \\
\hline High & $70(61.4)$ & $22(40.7)$ & $37(28.7)$ \\
\hline \multicolumn{4}{|l|}{ Approach to life } \\
\hline Optimist & $63(54.8)$ & $31(56.4)$ & $58(44.6)$ \\
\hline Pessimist & $2(1.7)$ & $2(3.6)$ & $11(8.5)$ \\
\hline Mixed & $50(43.5)$ & $22(40.0)$ & $61(46.9)$ \\
\hline
\end{tabular}


Table 2. Means and standard deviations for biological parameters by occupational group with results of one-way analysis of variance.

\begin{tabular}{|c|c|c|c|c|c|c|c|c|}
\hline & \multicolumn{2}{|c|}{ Professionals } & \multicolumn{2}{|c|}{ Soldiers } & \multicolumn{2}{|c|}{ Skill workers } & \multirow[b]{2}{*}{$\mathrm{F}$} & \multirow[b]{2}{*}{$p$} \\
\hline & Mean & SD & Mean & SD & Mean & SD & & \\
\hline Age & 53.1 & 10.3 & 43.9 & 8.1 & 49.8 & 9.1 & 17.5 & 0.001 \\
\hline Height & 173.8 & 6.6 & 175.7 & 6.9 & 171.9 & 6.4 & 6.5 & 0.002 \\
\hline BMI & 27.2 & 3.2 & 28.2 & 4.6 & 27.1 & 3.7 & 1.7 & 0.193 \\
\hline WHR & 0.93 & 0.06 & 0.90 & 0.06 & 0.93 & 0.06 & 4.4 & 0.014 \\
\hline Systolic BP & 138.0 & 17.8 & 135.5 & 19.7 & 137.2 & 22.1 & 0.3 & 0.759 \\
\hline Diastolic BP & 86.6 & 9.5 & 88.2 & 10.4 & 88.2 & 12.5 & 0.6 & 0.540 \\
\hline EHC & 69.8 & 21.3 & 84.5 & 6.9 & 66.2 & 22.9 & 15.2 & 0.001 \\
\hline $\mathrm{TCH}$ & 227.9 & 39.3 & 226.3 & 43.7 & 215.5 & 46.7 & 2.5 & 0.085 \\
\hline TGL & 174.5 & 95.8 & 203.5 & 137.4 & 175.0 & 117.9 & 1.3 & 0.265 \\
\hline HDL & 52.3 & 12.2 & 53.0 & 13.3 & 54.5 & 13.8 & 0.8 & 0.439 \\
\hline LDL & 142.8 & 34.7 & 134.1 & 35.0 & 123.9 & 35.1 & 7.0 & 0.001 \\
\hline Glucose & 105.7 & 13.5 & 106.7 & 21.2 & 115.8 & 22.1 & 1.7 & 0.201 \\
\hline IGF-1 & 321.8 & 83.7 & 345.1 & 83.8 & 293.0 & 82.9 & 7.7 & 0.001 \\
\hline TT & 4.3 & 1.4 & 4.2 & 1.4 & 4.3 & 1.5 & 0.1 & 0.949 \\
\hline FT & 17.3 & 5.0 & 19.1 & 5.9 & 18.2 & 5.7 & 2.1 & 0.125 \\
\hline SHBG & 32.9 & 11.3 & 28.1 & 11.1 & 32.8 & 11.7 & 3.5 & $\mathbf{0 . 0 3 1}$ \\
\hline E2 & 20.5 & 6.4 & 21.5 & 5.5 & 20.0 & 6.1 & 1.2 & 0.306 \\
\hline DHEAS & 1739.3 & 1102.7 & 2319.3 & 1063.2 & 1968.2 & 1105.8 & 4.7 & 0.010 \\
\hline
\end{tabular}

all was highest for soldiers, with about one-third reporting that they abstained. $98.1 \%$ of the soldiers reported spending their leisure time engaged in physical activity. Only $85.1 \%$ of the skilled workers reported doing so. Overall, skilled workers showed the tendency to more frequent cigarette smoking, alcohol drinking and spending their leisure time in a sedentary fashion than individuals in the other two groups.

Men's work style analysis showed that the vast majority of professionals and soldiers perform work that requires making independent decisions (95.7 and 96.4\%, respectively), and were associated to personnel management (74.8 and 87.3\%, respectively). In turn, the work performed by skilled workers was more often repetitive (63.9\%) and physically demanding (74.6\%). Psychological condition of the professionals and soldiers was better than skilled workers. The highest level of general life satisfaction declared $61.4 \%$ of professionals, $40.7 \%$ of soldiers and $28.7 \%$ skilled workers only. Until $8.5 \%$ of workers declared that they were pessimists, while among professionals and soldiers, this percentage ranged from 1.7 to $3.6 \%$.

Values for the general biological parameters for each occupational group are presented in Table 2. Significant differences between occupational groups were found for seven out of the 17 parameters tested. Professionals had a significantly higher LDL level. Soldiers group were taller and had a lower waist-to-hip ratio. They had the highest values for eyehand coordination. They had the highest levels for triglycerides IGF-1 and DHEAS, and the lowest levels for SHBG. Skilled workers were shorter, and had the lowest values for eye-hand coordination and IGF-1.

More than half of the general biological parameters measured showed a significant correlation with calendar age (Table 3). Correlation coefficients ranged from 0.01 to 0.55 , with a high level of significance. The parameters with the highest correlation coefficients were DHEAS level $(r=-0.5496)$ and eye-hand coordination $(r=-0.5089)$. Although some of the parameters showed no age dependency in this study, they were included in the further analysis of the
Table 3. Correlation coefficients $(r)$ for biological parameters with age.

\begin{tabular}{lc}
\hline Variables & $r$ \\
\hline Height & $-0.30^{* * *}$ \\
BMI & 0.05 \\
WHR & $0.19^{* * *}$ \\
Systolic BP & $0.22^{* * *}$ \\
Diastolic BP & 0.02 \\
EHC & $-0.51 * *$ \\
TCH & -0.02 \\
TGL & $-0.14 * *$ \\
HDL & 0.04 \\
LDL & 0.05 \\
Glucose & -0.08 \\
IGF-1 & $-0.34 * * *$ \\
TT & 0.01 \\
FT & $-0.33^{* * *}$ \\
SHBG & $0.38^{* * *}$ \\
E2 & -0.09 \\
DHEAS & $-0.55^{* * *}$ \\
\hline$* p \leq 0.05 ;$ & \\
$* * p \leq 0.01 ;$ & \\
$* * * p \leq 0.001$. &
\end{tabular}

data because such dependencies had been reported previously in the literature.

Biological age for the general biological parameters by occupational group is presented in Figure 1. The results were generally similar for professionals and soldiers, and individuals in these groups had a lower biological age than skilled workers. This was particularly true for systolic and diastolic blood pressure, glucose level and eye-hand coordination. Skilled workers tended to be shorter and thinner, based on BMI and WHR. BMI was highest in soldiers, which may indicate that these individuals tended to have a better nutritional status and the higher content of muscle tissue in bodies, which leads to more massive body build. The results obtained indicated that professionals and soldiers had significantly lower values for total cholesterol, LDL and 
Figure 1. Biological age profiles for general biological parameters by occupational group. (Significant values according to Student's $t$-test: $* p \leq 0.05 ; * * p \leq 0.01 ; * * * p \leq 0.001)$.

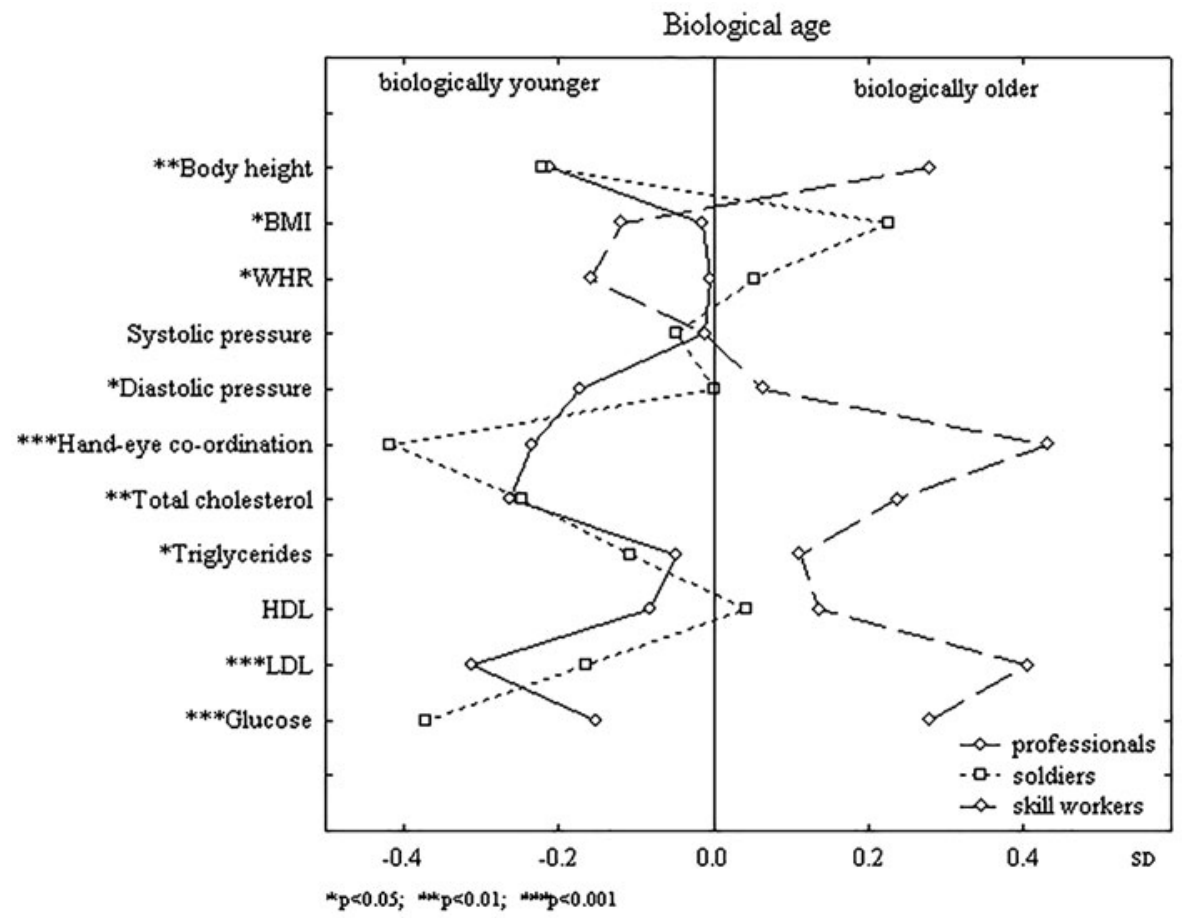

Figure 2. Biological age profiles for hormonal parameters by occupational group. (Significant values according to Student's $t$-test: $* p \leq 0.05 ; * * p \leq 0.01 ; * * * p \leq 0.001)$.

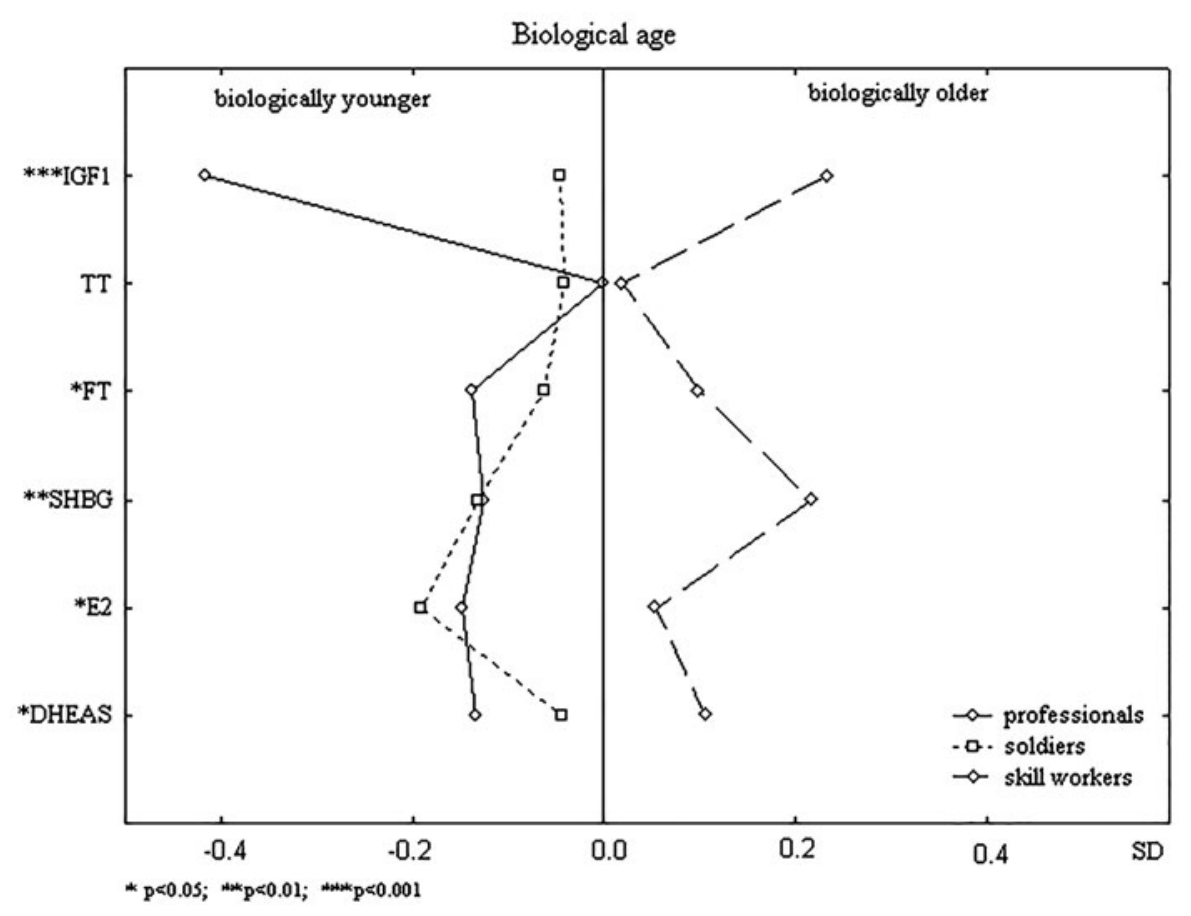

triglycerides, which meant that they had a lower biological age than skilled workers for these parameters.

Biological age for the hormonal parameters by occupational group is presented in Figure 2. For almost all of the parameters measured, biological age was lower than calendar age for professionals and soldiers, and higher than calendar age for skilled workers. For most of the parameters, biological age was significantly lower for professionals than for the other two groups. Professionals had the highest values for IGF-1, FT and DHEAS, whereas skilled workers had the lowest levels. Skilled workers group also had the lowest levels of indicators of anabolic processes such as testosterone, estradiol and DHEAS, and thus a higher biological age than individuals in the other groups for these parameters.

\section{Discussion}

In general, relative biological age was lowest for professionals and highest for skilled workers for the general biological and hormonal parameters measured. Professionals exhibited the 
most favorable values for blood pressure, lipid fractions, glucose and androgens. They were significantly taller than skilled workers. Although they had values for BMI and distribution and eye-hand coordination that were intermediate between the other two groups, their biological age for these parameters was still less than their calendar age. For skilled workers, biological age was high for blood pressure, lipid fractions and glucose. They also had the lowest levels for eyehand coordination and androgenic hormones. They were shorter and thinner than individuals in the other two groups. The results for soldiers are harder to characterize. They had the highest values for BMI and WHR, and the best values for eye-hand coordination. Values for the other general biological and hormonal parameters were generally closer to those for professionals.

Two hypotheses could be used to explain these differences in biological condition among the occupationally active men examined. The first hypothesis states that the occupation chosen may have been selected on the basis of defined psychophysical traits. It means that some men would have been predisposed to choose a certain occupation based on their combination of defined physical traits, constitution, hormonal profile or personality profile more than men lacking these traits would. It has often been suggested that defined psychophysical traits may to a certain degree determine the development of vocational interest in young men, and thus affect the choice of the occupation and concrete social role during adult life. There is also evidence that, besides character traits, physical traits like height and body build or the level of certain hormones may predispose them to pursue certain occupations. Furthermore, many studies have shown that men who are tall and thin are more likely to fulfill certain social roles. For example, presidents of the United States have been taller on average than the American population at large [28].

Studies carried out by behavioral endocrinologists have shown that choice of occupation is affected by the level of androgenic hormones, particularly testosterone. This is consistent with the selection hypothesis. Testosterone level is a powerful predictor of the need for non-aggressive domination, which often manifests itself as anti-social behavior, including rebellion against authority and law breaking [29]. High testosterone levels are also correlated with aversion to risk and threshold for conflict, fear and stress [30]. They are also correlated with better performance by high-echelon employees who make important decisions [31]. Furthermore, some studies have found that men with high testosterone levels are more likely to make utilitarian decisions that promote a certain social benefit regardless of the increased costs of their decisions, for example, in terms of harder work [32]. This had been used to explain the fact that men with high testosterone levels achieve greater success on Wall Street, where achieving success means being able to accept the costs associated, for example, hard work and lack of friends [31]. Men with high testosterone levels who worked in lower stations were not as successful, whereas men with low testosterone levels who worked in higher stations were less emotionally about their status and were also not as successful [33].
Individual genetically determined differences in total testosterone level may have a subliminal and intuitive effect on the choice of an occupation in which a given individual best realizes himself, based on internal feelings, and in which he/she achieves the greatest success. In the present study, the differences between occupations groups in the mean level of total testosterone were not statistically significant. Nevertheless, the trend observed was consistent with the studies discussed above. Soldiers had the highest levels of total testosterone, while skilled workers had the lowest. A clearer picture emerges with regard to the level of free testosterone, which may be a better predictor than total testosterone of the need for domination. Levels of free testosterone were significantly higher in professionals and soldiers than in skilled workers. Members of these occupational groups held higher, more prestigious positions that require making important decisions. Bearing in mind the high correlation between free testosterone and age, one may suppose that, at the time they made the choice about their future career at about age 20, their free testosterone levels were even higher, and may have been the reason they chose the occupations they did.

Another argument supporting the selection hypothesis is that the men had not finished growing when they chose their future occupations. On the basis of the sample in the present study, we can say that taller men became professionals and soldiers, and shorter men became skilled workers. This confirms studies showing selection of social groups on the basis of height $[34,35]$.

The second hypothesis explaining the observed relationship between biological condition and occupational status states that the current biological condition of the men examined is a result of the long-term effects of the work they perform. Numerous studies have shown that belonging to a particular social or occupational group is associated with developing a combination of behavioral patterns that are characteristic for that group, which in turn affects lifestyle [34-36]. Furthermore, the long-term action of certain behaviors or stimuli, such as stress, can affect the psychological state and biological condition of workers. Long-term effect of hazardous lifestyle typical for the group of individuals or group of workers, for example smoking, drinking, and poor diet, all of which are independent predictors of cardiovascular disease [37]. Besides, it was shown age and social position constitute major determinants of the intensity of aging males' symptoms in Poland [36]. In our study, the oldest men (professionals) had the lowest relative biological age for the general biological and hormonal parameters measured. Therefore, it also confirmed the impact of social position on the biological condition.

One of the basic elements describing the nature of work is decision making, or autonomy over how one performs one's work. This is a main factor that distinguishes the three occupational groups in this study. The level of chronic stress is high in occupations that do not allow for autonomous decision making and are highly subject to supervision and control from occupation superiors. Many studies had indicated that work-related stress or general life dissatisfaction are associated with increased risk of coronary heart 
disease [7,38]. One study examined cardiovascular risk in men in six contrasting service occupations: freight handlers, aircraft mechanics, air traffic controllers, physicians, waiters and symphony musicians. The number of risk factors was greatest in waiters, the group reporting the most unfavorable working conditions. On the other hand, the number of risk factors was low in physicians, who reported high latitude in decision making and many emotional reactions in their daily life. They also had relatively high cortisol levels and low prolactin levels [39]. The poor parameters for biological condition and the suboptimal poor hormonal profiles in the skilled workers in the present study was the long-term effect of occupying a low position in the social hierarchy. The biological effect of chronic stress includes imbalance in neuro-endocrine parameters that are generally considered to be biomarkers for stress [24]. As expected, testosterone levels tended to be higher in soldiers, whose work involves a high level of decision making and responsibility.

Adverse working conditions can also have a negative effect on the biological condition of workers. In the present study, the skilled workers were subjected to the least favorable external work conditions and were required to exert the most physical exertion, often while standing. The nature of this work, together with the fact that skilled workers had the lowest level of recreational physical activity, is reflected in the poor state of the cardiovascular system and in the poor overall biological condition of these workers. In addition, among the skilled workers the weakest mental condition was found, for example, the least frequently they were optimists, the most frequently pessimists, the lowest number of them reported high life satisfaction. It had been proven that such mental factors may also influence physical functioning [38,40,41]. For instance, general life satisfaction can detect a group dissatisfied men from the general population with a higher risk of having poorer health parameters $[38,40]$. The skilled workers had the highest systolic and diastolic blood pressures and the highest levels of total cholesterol, triglycerides and glucose. On the contrary, subjects with high life satisfaction, have reduced the risk poor health parameters and especially the risk of coronary heart disease $[38,40,41]$. Therefore, the high life satisfaction and general psychological well-being declared by professionals could also have positive influence on their health and biological age.

The two hypotheses presented here are not mutually exclusive. In fact, they can be expected to act synergistically. Inborn biological predispositions can be expected to be reinforced in a chosen occupation in accordance with the discussed mechanisms. When examining individuals who are advanced in their careers, it is impossible to distinctly separate inborn predisposition to perform a given type of work from traits acquired while performing the work. Regardless of the functioning mechanism, the exact knowledge of the differences in biological conditions workers from different occupational status should provide valuable information for both the occupational physicians and politicians making health care a right for those employees so that employees are able to work effectively and healthily.

\section{Acknowledgements}

The authors would like to thank the authorities of the Silesian Center for Preventive Medicine DOLMED S.A in Wroclaw for the possibility to the collecting data.

\section{Declaration of interest}

Authors declare that they have no conflict of interest.

\section{Funding}

This work was supported by the National Science Center in Poland, followed by the grant number [N N303 543 239].

\section{Ethical approval}

All procedures performed in studies involving human participants were in accordance with the ethical standards of the institutional and/or national research committee and with the 1964 Helsinki declaration and its later amendments or comparable ethical standards.

\section{References}

1. Bartley M, Owen C. Relation between socioeconomic status, employment, and health during economic change, 1973-93. BMJ 1996;313:445-9.

2. Modini M, Joyce S, Mykletun A, et al. The mental health benefits of employment: results of a systematic meta-review. Australas Psychiatry 2016;24:331-6.

3. Koziel S, Lopuszanska M, Szklarska A, Lipowicz A. The negative health consequences of unemployment: the case of Poland. Econ Hum Biol 2010;8:255-60.

4. Stansfeld S, Candy B. Psychosocial work environment and mental health - a meta-analytic review. Scand J Work Environ Health 2006; 32:443-62.

5. Yu W, Lao XQ, Pang S, et al. A survey of occupational health hazards among 7,610 female workers in China's electronics industry. Arch Environ Occup Health 2013;68:190-5.

6. Rosenthal T, Alter A. Occupational stress and hypertension. J Am Soc Hypertens 2012;6:2-22.

7. Thayer JF, Verkuil B, Brosschot JF, et al. Effects of the physical work environment on physiological measures of stress. Eur J Cardiovasc Prev Rehabil 2010;17:431-9.

8. Salonen JT, Puska P, Tuomilehto J. Physical activity and risk of myocardial infarction, cerebral stroke and death: a longitudinal study in Eastern Finland. Am J Epidemiol 1982;115:526-37.

9. Salonen JT, Slater JS, Tuomilehto J, Rauramaa R. Leisure time and occupational physical activity: risk of death from ischemic heart disease. Am J Epidemiol 1988;127:87-94.

10. Krause N, Brand RJ, Kaplan GA, et al. Occupational physical activity, energy expenditure and 11-year progression of carotid atherosclerosis. Scand J Work Environ Health 2007;33:405-24.

11. Kristal-Boneh E, Harari G, Melamed S, Froom P. Association of physical activity at work with mortality in Israeli industrial employees: the CORDIS study. J Occup Environ Med 2000;42: 127-35.

12. Menotti A, Seccareccia F. Physical activity at work and job responsibility as risk factors for fatal coronary heart disease and other causes of death. J Epidemiol Community Health 1985;39: 325-9.

13. Lapidus L, Bengtsson C. Socioeconomic factors and physical activity in relation to cardiovascular disease and death. A 12 year follow up of participants in a population study of women in Gothenburg, Sweden. Br Heart J 1986;55:295-301.

14. Hansen AM, Kaergaardb A, Andersenb JH, Netterstrømc B. Associations between repetitive work and endocrinological indicators of stress. Work Stress 2003;17:264-76.

15. Krause N, Lynch JW, Kaplan GA, et al. Standing at work and progression of carotid atherosclerosis. Scand J Work Environ Health 2000;26:227-36. 
16. Purdue MP, Hutchings SJ, Rushton L, Silverman DT. The proportion of cancer attributable to occupational exposures. Ann Epidemiol 2015;25:188-92.

17. Rushton L, Hutchings S, Brown T. The burden of cancer at work: estimation as the first step to prevention. Occup Environ Med 2008; 65:789-800.

18. Bonde JP. Psychosocial factors at work and risk of depression: a systematic review of the epidemiological evidence. Occup Environ Med 2008;65:438-45.

19. Ghaddar A, Omar KH, Dokmak M, et al. Work-related stress and urinary catecholamines among laboratory technicians. J Occup Health 2014;55:398-404.

20. Stansfeld SA, Pike C, McManus S, et al. Occupations, work characteristics and common mental disorder. Psychol Med 2013;43: 961-73.

21. Kivimäki M, Nyberg ST, Batty GD, et al. Job strain as a risk factor for coronary heart disease: a collaborative meta-analysis of individual participant data. Lancet 2012;380:1491-7.

22. Zitzmann M, Nieschlag E. Testosterone levels in healthy men and the relation to behavioural and physical characteristics: facts and constructs. Eur J Endocrinol 2001;144:183-97.

23. Nakata A, Takahashi M, Irie M, Swanson NG. Job satisfaction is associated with elevated natural killer cell immunity among healthy white-collar employees. Brain Behav Immun 2010;24:1268-75.

24. Hansen AM, Larsen AD, Rugulies R, et al. A review of the effect of the psychosocial working environment on physiological changes in blood and urine. Basic Clin Pharmacol Toxicol 2009;105:73-83.

25. McEwen BS. Central effects of stress hormones in health and disease: Understanding the protective and damaging effects of stress and stress mediators. Eur J Pharmacol 2008;583:174-85.

26. Vermeulen A, Verdonck L, Kaufman JM. A critical evaluation of simple methods for the estimation of free testosterone in serum. J Clin Endocrinol Metab 1999;84:3666-72.

27. Borkan GA, Norris AH. Assessment of biological age using a profile of physical parameters. J Gerontol 1980;35:177-84.

28. Sommers PM. Is presidential greatness related to height? Coll Math J 2002:33:14-16.
29. Mazur A, Booth A. Testosterone and dominance in men. Behav Brain Sci 1998;21:353-63.

30. Booth A, Johnson D, Granger D. Testosterone and men's health. J Behav Med 1999;22:1-19.

31. Coates JM, Herbert J. Endogenous steroids and financial risk taking on a London trading floor. Pnas 2008;104:6167-72.

32. Carney D, Mason MF. Decision making and testosterone: when the ends justify the means. J Exp Soc Psychol 2010;46: 668-71.

33. Josephs RA, Sellers JG, Newman ML, Mehta PH. The mismatch effect: when testosterone and status are at odds. J Pers Soc Psychol 2006;90:999-1013.

34. Bielicki T, Waliszko H. Stature, upward social mobility and the nature of statural differences between social classes. Ann Hum Biol 1992;19:589-93.

35. Bielicki T, Szklarska A. Are social-class differences in stature partly genetic? A hypothesis revisited. Am J Hum Biol 2000;12: 97-101.

36. Jankowska EA, Szklarska A, Lopuszanska M, Medras M. Age and social gradients in the intensity of aging males' symptoms in Poland. The Aging Male 2008;11:83-8.

37. Lipowicz A, Łopuszanska M. Marital differences in blood pressure and the risk of hypertension among polish men. Eur J Epidemiol 2005;20:421-7.

38. Łopuszańska M, Szklarska A, Lipowicz A, et al. Life satisfaction and cardiovascular disease risk in Poland. Arch Med Sci 2013;9: 629-34.

39. Theorella T, Ahlberg-Hultena G, Sigalaa F, et al. A psychosocial and biomedical comparison between men in six contrasting service occupations. Work Stress 1990;4:51-63.

40. Łopuszańska-Dawid M. Life satisfaction and biological condition among Polish adults. J Res Pers; under review.

41. Røysamb E, Tambs K, Reichborn-Kjennerud $\mathrm{T}$, et al Happiness and health: environmental and genetic contributions to the relationship between subjective well-being, perceived health, and somatic illness. J Pers Soc Psychol 2003;85: $1136-46$. 